\title{
Dissimilarities in Social Support as Described by Swedish- and Foreign-Born Persons Diagnosed with Type 2 Diabetes and Living in Sweden
}

\author{
Katarina Hjelm ${ }^{*}$, Carina Berterö ${ }^{2}$ \\ ${ }^{1}$ Department of Social and Welfare Studies, Campus Norrköping, University of Linköping, Linköping, Sweden \\ ${ }^{2}$ Department of Medical and Health Sciences, Faculty of Health Sciences, University of Linköping, Linköping, \\ Sweden \\ Email: ${ }^{*}$ atarina.hjelm@liu.se
}

Received 17 December 2013; revised 23 February 2014; accepted 8 March 2014

Copyright (C) 2014 by authors and Scientific Research Publishing Inc.

This work is licensed under the Creative Commons Attribution International License (CC BY).

http://creativecommons.org/licenses/by/4.0/

(c) (1) Open Access

\begin{abstract}
Diabetes (DM) requires self-care that is demanding and may cause stress. Social support can buffer effects of stress. No previous study has been found comparing perceptions of foreign-born persons with DM, concerning the content of and need for social support with a population of origin. The aim was to compare the meaning of support and its impact on the life situation in Swedishand foreign-born persons diagnosed with type $2 \mathrm{DM}$ living in Sweden. A purposive sample of 74 persons; 34 foreign- and 40 Swedish-born, aged 32 - 80 years, diagnosed with type 2 DM, was included. The foreign-born persons were mostly Middle Eastern and Ex-Yugoslavian refugees. Mixed methods were used and data were collected by qualitative interviews and quantitative data collected by the Norbeck Social Support Questionnaire (NSSQ). Studying the figures measured by NSSQ, no significant differences were found according to gender but foreign-born men scored lower than Swedish, especially in emotional support and aid. The main findings showed that respondents, irrespective of origin, described the meaning of the concept of support mainly as information support in learning to manage DM. However, foreign-born persons also focused on medical support with regular follow-ups while Swedes emphasized the need for emotional support. Foreign- and Swedish-born persons are in general more similar than dissimilar in describing the meaning, need and impact of support. Irrespective of origin they want to learn to manage their disease and thus desire and need regular follow-up and information immediately from being diagnosed. Further studies are needed as the study is based on a limited sample.
\end{abstract}

\footnotetext{
*Corresponding author.
} 


\section{Keywords}

\section{Foreign-Born Persons; Individual Perceptions; Mixed Methods; Need Assessment; Social Support; Swedish Persons; Type 2 Diabetes Mellitus}

\section{Introduction}

The concept of social support has been studied to a limited extent within the area of diabetes mellitus (DM) [1] [2]. No study has been found comparing foreign-born persons' own perceptions of its content and what support that is needed in relation to the diabetic disease for a population of foreign origin.

The diabetic disease poses high demands on adaptation to the cornerstones of diabetes care: diet, exercise, medications, awareness, and self-management, and to life in general [3]. In foreign-born persons the acculturation process in the host country acts as an additional stressor, requiring further adaptation [4]. It also includes migrational background, experiences of uprooting, and broken or limited social networks negatively affecting health [5]-[7]. Social support is claimed to play an important role in self-management of DM [8] by influencing compliance with advice about management of the disease, and this influences glycaemic control [9] [10]. Limited social support has been clearly shown to be related to denial of the disease [11].

Sweden, like many other European countries, has become multicultural due to ongoing extensive global migration [12]. If the second generation of migrants (those with a parent born abroad) is also counted, almost 20\% of the population have a foreign background. The migrant population is heterogeneous, with over 200 different nationalities represented, although it is dominated by European labour migrants. Most immigrated in the postwar era on a voluntary basis to work in Swedish industry, and the largest groups originate from Finland and the former Yugoslavia. The immigration pattern changed in the mid-1980s to refugees; apart from former Yugoslavians, most of them originate from non-European countries in Asia, Latin America, the Middle East, and Africa. Persons from Iraq are now the largest group of non-European refugees. Thus, there is a great possibility of encountering persons with a foreign background in the Swedish health care system. The chance of encountering persons with a foreign background in diabetes care is further increased as those facing the greatest risk of being affected by the developing diabetes pandemic of type $2 \mathrm{DM}$ are migrants, populations of developing countries, minority populations, and disadvantaged communities in industrialized countries [13]. The increasing number of foreign-born persons is a challenge for the health care organization, and the question is whether support for persons of different origin differs and this is perceived to be satisfied.

From studies in work environments it is known that perceived high demands and low control often lead to frustration and stress, causing deteriorated health [14]. A person with DM stress may imply impaired glycaemic control, contributing to the development of micro- and macrovascular complications related to DM. However, the stress can be buffered with social support [14] [15]. Social support can be defined both quantitatively, in terms of the number of contacts with others, and qualitatively, in terms of the importance of the contacts and the content, e.g. material, informative, and emotional support and social anchorage for the individual. The theory of social resources forms the basis for social networks and social support and comprises interaction between human beings [15] [16]. The likelihood of positive health outcomes is greater if adequate support is perceived. Demographic and individual variables such as culture, sex, and age influence the degree of social support needed and its availability [17]. From these assumptions the Norbeck Social Support Questionnaire (NSSQ) has been developed [17]-[19], measuring three subscales of social support: affect, affirmation, and aid, along with functional network properties and recent losses of network members (for further details see Table 1).

In Swedish persons diagnosed with type $2 \mathrm{DM}$, the need for support was considered to be individual and related to age, gender and duration of the disease [1], while foreign-born persons with the same disease claimed it to be related to the severity of the disease, besides being individual [2]. The question then is whether there are other dissimilarities that need to be considered in diabetes care to enable persons with DM to be active in self-management. The aim of this study was to compare the meaning of support and its impact on the life situation in foreign- and Swedish-born persons diagnosed with type 2 DM and living in Sweden. The questions to be answered were: are there dissimilarities in perceived and experienced meaning, need and impact of support in relation to country of birth? How do the person's own descriptions of perceived support correspond to what has been delivered? 
Table 1. What is measured by the Norbeck Social Support Questionnaire (NSSQ).

\begin{tabular}{ll}
\hline Structural network properties & \\
Affect & Actions causing changes \\
Affirmation & The act of emotional confirmation \\
Aid & Giving assistance \\
& \\
Functional network properties & Number \\
& Duration \\
Recent losses of members in the network & Frequency \\
\hline
\end{tabular}

\section{Materials and Methods}

\subsection{Design}

A mixed-methods design using sequential qualitative and quantitative research methods was used to capture the whole meaning of the complex concept of social support [20] [21]. Data were collected in the two studied groups, foreign- and Swedish-born persons with type $2 \mathrm{DM}$, and then the results were compared.

The quantitative method consisted of persons filling in a self-reported questionnaire entitled the Norbeck Social Support Questionnaire (NSSQ). The self-report instrument, with closed questions, was designed to measure multiple dimensions of perceived social support [17] [18]. The NSSQ measures three main areas of social support: affect, affirmation and aid. The content of the domains in the questionnaire provided a framework for understanding the participants' own experiences and perceptions [17] [18].

Qualitative data were gathered through individual semi-structured face-to-face interviews allowing the informants to guide the content within a frame of questions. The interview guide was exploratory and aimed to reach the "insider (emic) perspective" to get a comprehensive and nuanced understanding of the meaning and implications of social support [21]. The content of the domains in the questionnaire provided a framework for understanding the participants' own experiences and perceptions [17] [18].

\subsection{Local Setting}

In Sweden diabetes care is organized with care delivered either in primary health care (PHC), or at a hospital, or both. Management of Type 2 DM is mainly provided in PHC but in the studied area, when patients were diagnosed with diabetes, they were referred to a hospital-based diabetes clinic for investigations and diabetes education. Subsequent care was delivered in PHC with referral to a hospital-based diabetes clinic for management of diabetes-related complications and attendance of diabetes classes.

\subsection{Participants}

A purposive sample of Swedish- and foreign-born persons, aged above 18 years and diagnosed with type 2 DM, was recruited by the staff at a hospital-based diabetes clinic. The clinic served persons with DM who were being managed in PHC centres and in the outpatient clinics at the hospital. Persons interested in participating filled in a reply coupon that was forwarded to the principal investigator, who contacted them to set a time and appropriate place for the interview. To cover a range of experiences, persons of different age and duration of DM were chosen to better understand the complexity of the concept [22] of social support.

\subsection{Ethical Considerations}

The study was approved by the Ethics Committee of the University of Lund, Sweden, and was carried out with written informed consent from the participants and in accordance with the Helsinki Declaration [23]. Arrangements were also made to contact a social welfare officer or a diabetes team if any respondent should react negatively in the interview situation and be in need of support.

\subsection{Data Collection}

\subsubsection{Interviews}

Data were collected by semi-structured interviews with the informants, conducted by a female diabetes specialist 
nurse (DSN), nor involved in management of the clients nor in the diabetes clinic. A pilot-tested interview guide was used ( $n=6$ persons), and further developed after being used in the Swedish-born group [1]. Three openended questions were used and focused on the meaning of the concept of support, its influence on the entire life situation when having DM, and what support was considered necessary. The interviews were held in secluded rooms outside the clinic, lasted about $1-1.5$ hours and were audio-taped. In the foreign-born group, when needed, an authorized interpreter of the same gender and speaking the same language as the informant was used and a word-for-word (sequential) interpretation technique was applied.

\subsubsection{Norbeck Social Support Questionnaire}

The self-report structured questionnaire, NSSQ, is based on a Likert scale. The informants rated each network member on three different subscales: affect, affirmation, and aid [17]-[19]. The instrument had been languageand culture-validated to fit Swedish circumstances [24] [25]. The NSSQ was answered by the informants after the interviews. The questions were read by the interviewer and translated by an interpreter if necessary, and the participant answered the questions one by one. The data collection procedure always followed this order to avoid any influence on the respondents' perceptions of how to describe support.

\subsection{Data Analysis}

\subsubsection{Qualitative Content Analysis}

The interviews were transcribed verbatim and the text was analysed using qualitative content analysis [26]. The content of the domains in the NSSQ — affect, affirmation, and aid — previously described [17] [27] provided a broad framework for understanding the informants' own perceptions and experiences of social support and assisted the deductive-inductive analysis [26]. Data not deductively covered by the framework formed the basis for inductively developing categories. When analysing data the aim was to be open to variation in data, and to search for patterns, themes, regularities and contradictions by comparing statements from different respondents [26] in each group. The results from each group of respondents, foreign- and Swedish-born persons, were then compared. Investigator triangulation, with analysis of data by two researchers independently, was used to increase the trustworthiness of the results [22], and high agreement was shown. In the event of disagreement, i.e. different nuances in wording, the findings were discussed until consensus was reached. Results are presented as categories with subcategories and illustrated by illuminative quotations to reach confirmability.

\subsubsection{Statistics}

Demographic variables have been summarized and are presented with median and range. All results are reported as means \pm standard deviation of the mean (SD). Differences in the subscales, composite variable scores on the NSSQ, and comparison of means of the independent groups were tested with analysis of variance (ANOVA) and Student's t-test. For categorical data the $\chi^{2}$ test was used to assess whether there was a significant association between each of the measures assessing social support and functional network properties, and for discontinuous variables Fisher's exact test was used [28] [29] when needed. P $<0.05$ was considered statistically significant [28]. The Statistical Package for the Social Sciences (version 15; SPSS) was used for the statistical analyses.

\section{Results}

The study population comprised 74 persons diagnosed with type 2 DM, 34 foreign-born (24 men and 10 women) and 40 Swedish-born persons (24 men and 16 women), aged 32 - 80 years (median 58 years) (Table 2). The foreign-born group included mainly persons originating from countries in the former Yugoslavia and the Middle East (n 34 vs 29), with a median time of residence in Sweden of 14.5 years (range 3 - 50 years). The duration of DM varied from 0.5 to 39 years (median 9 vs 9.5 in foreign- and Swedish-born) and most were treated with oral agents or diet (22/34 vs 18/40), and the number of persons treated with a combination of insulin and oral drugs was higher among Swedish- than foreign-born persons $(\mathrm{p}=0.03)$.

\subsection{Self-Reported Social Support and Networks Measured by NSSQ}

Small differences were found between the Swedish and the foreign-born group regarding married/cohabitants $72.9 \%$ vs $79.4 \%$, but the number of children showed a greater difference, $75.0 \%$ vs $97.1 \%$, and grandchildren $45 \%$ vs $55.9 \%$. Foreign-born persons had more children and grandchildren but limited social networks. These 
Table 2. Characteristics of the participants.

\begin{tabular}{|c|c|c|c|c|}
\hline \multirow[t]{2}{*}{ Variable } & \multicolumn{2}{|c|}{$\begin{array}{l}\text { Foreign-born persons diagnosed with } \\
\text { type } 2 \text { diabetes }\end{array}$} & \multicolumn{2}{|c|}{$\begin{array}{l}\text { Swedish-born persons diagnosed with } \\
\text { type } 2 \text { diabetes }\end{array}$} \\
\hline & $\begin{array}{l}\text { Women } \\
\mathrm{n}=10\end{array}$ & $\begin{array}{c}\text { Men } \\
n=24\end{array}$ & $\begin{array}{l}\text { Women } \\
\mathrm{n}=16\end{array}$ & $\begin{array}{c}\text { Men } \\
\mathrm{n}=24\end{array}$ \\
\hline Age (years) ${ }^{1}$ & $56(36-73)$ & $56.5(42-73)$ & $60(32-75)$ & $58(35-80)$ \\
\hline Duration of diabetes (years) ${ }^{1}$ & $7(1-17)$ & $12(2-36)$ & $9.5(2-39)$ & $8.5(0.5-28)$ \\
\hline \multicolumn{5}{|l|}{ Treatment n (\%) } \\
\hline Diet & $1(10)$ & $5(21)$ & $3(13.3)$ & $1(4.30)$ \\
\hline Oral drugs & $5(50)$ & $11(46)$ & $3(20.0)$ & $11(47.8)$ \\
\hline Insulin & $3(30)$ & $6(25)$ & $5(33.3)$ & $5(26.0)$ \\
\hline Combination of oral drugs and insulin & $1(10)$ & $2(8)$ & $5(33.3)$ & $5(21.7)$ \\
\hline \multicolumn{5}{|l|}{ Employment status n (\%) } \\
\hline Employed & $2(20)$ & $9(38)$ & $5(31.3)$ & $8(33.3)$ \\
\hline Unemployed & $2(20)$ & $5(21)$ & $1(6.3)$ & $1(4.2)$ \\
\hline Sick-leave & $1(10)$ & $2(8)$ & $2(12.5)$ & $1(4.2)$ \\
\hline Old-age pensioner & $3(30)$ & $8(33)$ & $8(50.0)$ & $13(54.2)$ \\
\hline Student & $2(20)$ & $0(0)$ & $0(0)$ & $1(4.2)$ \\
\hline \multicolumn{5}{|l|}{ Family circumstances n (\%) } \\
\hline Unmarried/living alone & $0(0)$ & $0(0)$ & $0(0)$ & $2(8.7)$ \\
\hline Married/cohabitant & $8(80)$ & 19 (79) & $13(81.3)$ & $16(69.6)$ \\
\hline Divorced & $1(10)$ & $4(17)$ & $1(6.3)$ & $3(13.0)$ \\
\hline Widowed & $1(10)$ & $1(4)$ & $2(12.5)$ & $2(8.7)$ \\
\hline Children n (\%) & $10(100)$ & $23(96)$ & $10(62.5)$ & $20(87.0)$ \\
\hline Grandchildren n (\%) & $7(70)$ & $12(50)$ & 5 (31.5) & $13(54.2)$ \\
\hline Percentage experience loss & 42 & 20 & 18 & 5 \\
\hline
\end{tabular}

${ }^{1}$ Values are median (range).

differences were significant $(\mathrm{p}=0.03)$. Swedish-born persons described better emotional support and support from their grandchildren $(p=0.04)$.

The number of old-age pensioners was higher in Swedish- than in foreign-born persons ( $52.5 \%$ vs $32.4 \%, \mathrm{p}=$ $0.03)$.

Studying the figures measured by NSSQ (Table 3), no significant differences were found according to gender and being foreign- or Swedish-born. Foreign-born men, however, score lower than Swedish-born men, especially in emotional support and aid. These figures show a trend but are not significant.

Three foreign-born persons did not respond to the NSSQ and one responded only partially, as they feared that the document could be used for other purposes than the intended one because of previous negative migration experiences. The participants who answered the NSSQ $(n=71)$ listed a total of 438 people in their networks. The mean number of people in each network was 6.51 (range 1 - 20) vs. 5.74 (range 1 - 14) in the Swedish- vs foreign-born group (Table 4). The foreign-born listed more health care providers $(p=0.044)$, and counsellors ( $p$ $=0.05$ ) as support than the Swedes. Friends were scored as support by the foreign-born, not significantly, but showing a trend $(\mathrm{p}=0.06)$.

\subsection{Qualitative Findings}

\subsubsection{Meaning of Support}

The meaning of support for foreign-born persons (F) was mainly expressed as medical support with regular control of the disease, and information support to get knowledge about managing the disease. Swedish-born persons (S) also focused on the need for information support but emphasized emotional support in managing the disease. They described support as when they felt confident in the situation by having opportunities to get into contact 
Table 3. Means and standard deviations of the scores on the Norbeck Social Support Questionnaire (NSSQ).

\begin{tabular}{lcccccc}
\hline \multicolumn{1}{c}{ Variable } & \multicolumn{2}{c}{ Foreign-born persons diagnosed with type 2 diabetes } & \multicolumn{3}{c}{ Swedish-born persons diagnosed with type 2 diabetes } \\
& $\begin{array}{c}\text { Total } \\
\mathrm{n}=31\end{array}$ & $\begin{array}{c}\text { Women } \\
\mathrm{n}=10\end{array}$ & $\begin{array}{c}\text { Men } \\
\mathrm{n}=21\end{array}$ & $\begin{array}{c}\text { Total } \\
\mathrm{n}=40\end{array}$ & $\begin{array}{c}\text { Women } \\
\mathrm{n}=16\end{array}$ & $\begin{array}{c}\text { Men } \\
\mathrm{n}=24\end{array}$ \\
& Mean (SD) & Mean (SD) & Mean (SD) & Mean (SD) & Mean (SD) & Mean (SD) \\
\hline NSSQ variable & & & & & & \\
Network size & $5.74(3.15)$ & $6.80(2.20)$ & $5.23(3.44)$ & $6.51(4.05)$ & $6.25(3.94)$ & $6.69(4.22)$ \\
Emotional support & $91.03(50.13)$ & $106.30(42.43)$ & $83.76(52.80)$ & $102.35(67.78)$ & $104.06(69.05)$ & $105.74(68.38)$ \\
Aid & $43.22(29.93)$ & $46.27(26.95)$ & $41.55(27.47)$ & $48.22(31.66)$ & $46.50(31.55)$ & $49.37(32.37)$ \\
Total function & $134.96(75.07)$ & $154.80(68.65)$ & $125.52(77.74)$ & $150.57(96.03)$ & $150.56(99.77)$ & $150.58(95.629)$ \\
Total network & $55.32(30.92)$ & $67.20(23.17)$ & $49.66(32.99)$ & $61.13(38.07)$ & $57.43(37.93)$ & $63.58(38.78)$ \\
\hline
\end{tabular}

Table 4. Social support, number of persons in the personal network, as listed by the participants $(\mathrm{N}=71)$.

\begin{tabular}{|c|c|c|c|c|}
\hline \multirow[t]{2}{*}{ Source of support } & \multicolumn{2}{|c|}{$\begin{array}{l}\text { Foreign-born persons diagnosed with type } 2 \text { diabetes } \\
\qquad \mathrm{n}=31\end{array}$} & \multicolumn{2}{|c|}{$\begin{array}{l}\text { Swedish-born persons diagnosed with type } 2 \text { diabetes } \\
\qquad \mathrm{n}=40\end{array}$} \\
\hline & Number & Percentage of total network & Number & Percentage of total network \\
\hline Spouse/partner & 22 & 12.4 & 31 & 12.0 \\
\hline Family & 84 & 47.2 & 112 & 43.1 \\
\hline Friends & 31 & 17.4 & 74 & 28.5 \\
\hline Workmates $^{1}$ & 9 & 5.1 & 14 & 5.4 \\
\hline Neighbours $^{1}$ & 2 & 1.1 & 3 & 1.2 \\
\hline Healthcare providers ${ }^{2}$ & 26 & 14.6 & 17 & 6.5 \\
\hline Counsellor $^{2}$ & 3 & 3 & 4 & 1.5 \\
\hline Minister/priest ${ }^{2}$ & 1 & 1 & 0 & 0 \\
\hline Total & 178 & & 260 & \\
\hline
\end{tabular}

${ }^{1}$ Could also be called non-professionals; ${ }^{2}$ Could also be called professionals.

with persons with whom they could discuss their situation, resolve problems in self-care, and obtain information concerning self-management. Swedish men also discussed the need for material support in terms of different aids for self-care e.g. blood-glucose monitors. Foreign-born women brought up the need for material/financial support as allowances for expensive food, drugs, and social insurance for widow/widowers, and elderly men focused on support in changing dietary habits and practical assistance in cooking. In general foreign-born persons claimed to have received limited support to a higher extent than Swedes.

"to learn to know how to organize my diabetes so that it will be good in my daily life. Planning to be able to manage diabetes, regular follow-ups... learn to know what factors contribute to control of blood sugar... and diet... what secondary factors make blood glucose go up or down..." (F)

“...to have a certain person that you can phone and ask... about diabetes and all that it will imply... to get help from her, that we can discuss what to do... to feel confident and know where to turn if there should be something... as when I started with insulin, how much to take and all these things. And just this with the diabetes disease, it is a lot and you need a lot of support in the beginning, both with dietary changes and all what it will mean to you... I have talked a lot with the diabetes nurse and the doctor." (S)

“...I have got... a machine (glucometer)... it is a very fine aid that I have also received.” (S)

“...particularly know when everything is expensive. At the beginning of this year it started to become much more... Especially food for persons with diabetes is expensive... three to four times more expensive... fruit and vegetables that are healthy are more expensive... Financial support is what you need.” (F)

"...after my husband (who had died) I got help from the Swedish Social Insurance Agency that supported with allowances.” (F)

"...if someone could come and help me with cooking... to show what sort of food to cook and how to cook it... a course...” (F) 


\subsubsection{Support Needed and Desired When One Has Diabetes}

Foreign-born persons experienced limited or non-existent support when and after being diagnosed with DM. Most had been diagnosed by physicians at health care centres and informed about the diagnosis and prescribed medications. They did not feel that they had received adequate support, both informative and emotional, until treated in a diabetes clinic or in PHC by staff specialized in diabetes care. The delay of time in this process was about a couple of weeks to some months in Swedes and in many foreign-born persons up to 1 - 2 years. Few respondents had met diabetes specialist nurses before contacts with the diabetes specialist clinics.

"It was at the health care centre... by pure chance they found I had diabetes... thought it was something else... She (the physician) prescribed Metformin... I fainted, was admitted to... the hospital... after two years I came to the health care centre. Interviewer: Did you get any education at the beginning? I got advice from my husband at home... this entrance (diabetes clinic)... that is aimed for persons with diabetes have helped me a lot. I: You have gone there for a diabetes class? I got a lot of support”. (F)

Most foreign-born persons had been diagnosed in Sweden, often as a secondary finding to other health problems for which they had been admitted to hospital or consulted a physician at a health care centre when feeling unwell but not suspecting DM. Even in Swedes DM was a secondary finding; women were predominantly diagnosed in PHC centres while males often were admitted to hospital. The reactions to receiving the diagnosis varied from being surprised to worries, fear, or not knowing what it was among foreigners. Swedes reacted similarly but seemed more knowledgeable, and several described being left alone with their worries.

An all-pervading theme in the interviews was the perceived lack of competence and limited knowledge about diabetes among health care staff encountered in PHC or at private clinics. The informants thus spoke of a lack of information support. When being managed by staff specialized in diabetes care in PHC or at hospitals, adequate support was perceived in both groups.

"... he (physician in private clinic) just increased the dose more and more and I didn't get any information, no support or anything... and the doctor at the hospital when he saw the test values he contacted the department of endocrinology and there I got wonderful support. Fantastic! ... all the contact with the diabetes specialist nurses... wonderful support. I really got information, they cared, easy to access, I could phone and they called back the same day." $(S)$

Unsupportive situations were rarely described by foreign-born persons, but if described the content was shared with Swedes discussing relations and communication with the physician. There were descriptions of physicians not listening or attending to the patients, and Swedes also added lack of competence.

"...this physician and I had some discrepancy. I wanted to change insulin. I told her that... I felt it was meaningless, it was a waste of time to sit and tell her something as she didn't listen, nor did she answer my questions." (S)

When describing situations perceived as supportive, Swedes focused on emotional and information support in discussions with health professionals and courses in diabetes care and material support as an aid to self-monitoring. Examples mentioned mainly concerned regular follow-ups by a diabetes specialist nurse or physician. Regular follow-ups were also emphasized by foreign-born persons but combined with information support such as knowledge about the disease and the chance to pose questions. Women in both groups, particularly Swedes, discussed lack of support and being disappointed with lack of support from health professionals in PHC, who were described as having limited competence in diabetes care.

“...to establish what you have (the diagnosis)... to get medication and equipment to be able to manage oneself... and then they have knowledge and I am impressed by that... have been on a course for five days... to take with others. Then you recognize that for him it was a real problem... so you get a picture of what is normal..." $(S)$

"...it was an interesting thing (course) where we learned to cook good food... to realize that healthy food doesn't need to be boring... when they checked my blood values... It was staff who were engaged and answered questions... it is not easy to change lifestyle... my doctor checks the long-term blood glucose, but to be regularly checked..." (F)

In the foreign-born group, persons mentioned as important sources of support were mainly professional care givers such as diabetes specialist nurses and physicians, while Swedes emphasized the influence of their spouse or family. Swedish men combined the popular sector (family/friends) with professional care givers, which was stated to a limited extent in women. Elderly foreign-born men ( $>65$ years) focused more strongly on their wife and daughters (popular sector) but also used professional care givers. 
In both groups the respondents perceived support to be individual, varying according to gender and age. Males were described as needing more support than females, and the difference was explained by the fact that that females "have better networks than males". Foreign-born persons also referred to "males having better knowledge and being more emotionally oriented". In this group the severity of disease was perceived as influencing the need of support. Over time most respondents believed that the "need of support will increase as the status of disease deteriorates".

Support desired was in both groups mainly medical support in terms of "adequate management" and "regular follow-ups" by staff with competence in diabetes care combined with information. Foreign-born persons also added the importance of financial support, e.g. for expensive food, and getting a job. Some foreign-born women also discussed the possibility of part-time work or retirement to be able to take care of and support relatives. Elderly foreign-born men (>65 years) also desired practical support with cooking.

"The best support... should be if someone could come and help me with cooking. Not regularly, just to show what kind of food I should cook and how to cook it and so on. Theoretically they say that I should change this one and that one and do like that or that... But I am the kind that learns much better if I can watch someone doing it, then I can stand there and observe. So that one can at the same time work out what ingredients to use and in what way... A course to learn to cook food, or I wonder if I should call her on TV 3 with the programme 'You Are What You Eat'... to show what to eat and how to do it." (F)

\subsubsection{Support Influencing the Entire Life Situation When One Has Diabetes}

Most respondents stated that the support perceived and given had a positive influence on their entire life situation. Many of the foreign-born persons expressed satisfaction with being cared for in Sweden and compared this with the health care system in their home country, which gave limited support in contrast to a more patient-centred and service-oriented attitude in Sweden which positively influenced their health. Elderly foreign-born men ( $>65$ years) said that the support made them feel better. Persons of working age discussed how the support given made them learn to live with and manage DM and thus live longer, better and healthier.

Other important factors in relation to the need for support in diabetes that also affected the total life situation of the informants were, among foreign-born persons, the ability to communicate. The need to use interpreters and information material in their own native language was discussed, particularly among Arabic-speaking persons. In the Swedish group many discussed the importance of information about news in diabetes care, and several expressed frustration and disappointment over deteriorated quality in diabetes care due to limited economic resources related to an increasing number of new cases.

\section{Discussion}

This study is unique in that it compares migrants' own perceptions of the content of social support and what support is needed in relation to the diabetic disease and the population of origin: foreign- vs Swedish-born persons; comparisons to previous studies will therefore only be partially. The main findings showed that respondents, irrespective of origin, described the meaning of the concept of support as mainly concerning information support in learning to manage diabetes. However, foreign-born persons also focused on medical support in terms of regular follow-ups, while Swedes emphasized the need for emotional support. Foreign-born respondents and Swedish females said they had received limited or non-existent support when diagnosed with diabetes, irrespective of the year when diagnosed, and particularly when treated outside specialized diabetes care. Adequate support was perceived when managed at specialized diabetes clinics but for many foreign-born persons there was an information gap and a time delay of 1 - 2 years from diagnosis through referral until reaching a specialist. Irrespective of origin, respondents desired medical support by regular follow-ups and foreign-born persons also desired economic support for high expenses for drugs and food and ability to communicate and be informed in the native language. The NSSQ measurement showed that foreign-born men scored lower figures on emotional support and aid than Swedes. The network size was quite similar to that of the Swedes but the foreign-born had to a higher extent lost an important relationship during the last year and listed more health care providers and counsellors as support.

Interesting but alarming in this study is that the respondents, irrespective of origin, desire information to be able to manage DM but that adequate information support is not given until being managed in specialized diabetes care, which is delayed by $1-2$ years in foreign-born compared to $1-2$ weeks or a couple of months in 
Swedish-born persons. As in previous investigations of persons with DM, males experienced better support than females [30] and because of a more severe disease pattern they seemed to a higher extent to be admitted to hospital and thus got into contact with specialized diabetes care earlier. The question is why there is an information gap and delay in the health care process as there are national guidelines for diabetes care [31], recommending an organization with specialized diabetes care teams to be responsible for management of type 2 DM in PHC and particularly focusing on patient education. Limited competence in diabetes care in health professionals in PHC and lack of continuity of staff have been discussed by diabetic patients [30] [32], possibly related to lack of specialized staff in diabetes care and shortage of staff in PHC in general [33]. The results here also indicated that the unsupportive situations described were related to poor communication and relations with physicians, previously claimed to influence perceived quality of care [1].

Another important influencing factor is language barriers, as several persons in this study desired more communication possibilities in their own language. Language barriers can lead to delayed or inappropriate care [34].

The results also showed, in accordance with previous investigations of migrants, that foreign-born persons had weaker social networks [5]-[7] and thus described having less emotional aid than Swedes. Although they seemed to compensate for this deficiency with more contacts with health care staff and counsellors, this needs to be attended to as the higher contact frequency might be related to the fact that they had lost an important contact in their network during the previous year. Migrants in this study are a particularly vulnerable group of persons both as regards the information gap and time delay of adequate information support and the limited economic resources influencing the appropriate treatment of DM with drugs and the choice of healthy food, and thus negatively affecting health. Costs of healthy food recommended for persons with DM (as well as the population in general) are higher than for other types of food [35]. Many migrants in Sweden, particularly those originating from non-European countries, live with limited economic resources due to unemployment and dependency on social allowances, which needs to be taken into consideration in diabetes care to give adequate support [35].

As Swedes perceived better emotional aid, they might get more support to manage their DM despite the time delay in information. In several previous studies migrants with DM [36]-[38] have discussed lack of self-help groups for patients, e.g. diabetes associations, for exchange of disease experiences and information with other persons in the same situation. All kinds of health professionals need to become aware of migrants' need for support, particularly information, and thus refer to the right person and develop an organization to deliver adequate information from the first moment. Patients in this study clearly indicate that they want to learn to manage their DM and have an underutilized potential for self-care which need to be used.

The studied foreign-born group mainly comprised persons originating from the former Yugoslavia and the Middle East with a median time of residence in Sweden of about 15 years and thus, in comparison to the Swedish migrant population, reflects a refugee population of later date [12]. The sample is thus biased, but as previous studies concerning diabetes in foreign-born persons in Sweden have shown a higher prevalence in nonEuropean refugee groups, e.g. Middle Easterners [39] [40], than in European labour migrants [41], this is to be expected. The foreign-born group also includes only one female aged above 65 years indicating an age bias. However, the migrant population comprises a lower proportion of women and is younger in comparison to the Swedish population [12].

The number of respondents might be seen as a limitation as regards statistical analyses [28]. However, the collection of quantitative data was not intended for statistical generalizations but instead used the principle of complementarity to obtain a more complete understanding of the complex concept of support [21] [22].

Some of the foreign-born informants did not respond to the self-reported instrument (NSSQ) or just some parts of it, as they feared disclosing their opinions and that the document might be used for other purposes than intended, which was related to previous migrational experiences. The studied population represents migrants in Sweden being affected by type 2 diabetes and as data have been carefully collected and analysed the results can be transferred to other groups similar in characteristics [22].

The findings of this study clearly show the importance of developing a health care organization for persons diagnosed with diabetes, irrespective of origin, so that they are not placed in a situation without adequate support in order to handle the new circumstances and are able to manage the disease. All persons diagnosed with DM, irrespective of origin, need to be managed in diabetes care delivering adequate information support without any delay from the first moment of being diagnosed. Further, it also needs to be investigated whether diabetes care is not delivered on equal terms to foreign- and Swedish-born persons with DM. According to the Swedish Health and Medical Services Act (1982:763) [42], health care should be delivered on equal terms for all persons 
irrespective of gender, race, and religious background, and therefore the needs of certain vulnerable groups such as migrants' need for support, particularly information, needs to be satisfied without any delay and under circumstances where the person has the possibility to communicate properly, aided by a translator if needed, to be completely understood. This is particularly important in the light of the emerging diabetes pandemia with the aim of promoting and maintaining health to prevent the development of costly diabetes-related complications, as the disease entails a major socioeconomic burden both to the society and to the individual [43]. In diabetes care it is also of the utmost importance to consider the influence of structural factors in society, as determinants of health, such as socioeconomic factors, influence advice received concerning healthy food appropriate for persons with DM at reasonable prices [44]. It is also important to act for further studies of the influence of social determinants on health and the development of a society with a public health policy striving for healthy lifestyle habits at limited costs [45].

\section{Conclusion}

In conclusion, foreign- and Swedish-born persons are in general more similar than dissimilar in describing the meaning, need and impact of support. Irrespective of origin, persons with DM want to learn to manage their disease and thus desire and need regular follow-up and information immediately on being diagnosed. An important dissimilarity is that foreign-born persons get more limited support from health care, both information and financial assistance, and it is given after a longer time delay. Foreign-born persons also have more limited resources to obtain support from their closest network. Being a refugee, losing your natural social network and family members who can be close to you and support you forces a person to adapt to a new situation as well as new circumstances; being diagnosed with an illness such as type 2 DM put higher demands of adaptation on the person which might negatively affect health. However, further studies are needed as the study is based on a limited sample.

\section{Acknowledgements}

We would like to thank Associate Professor Jan Apelqvist for helpful criticism and advice in planning the study. This work was supported by grants from SvenskaDiabetesförbundet (The Swedish Diabetes Association) and the research profile AMER (Labour market, Migration and Ethnic Relations), University of Växjö, Växjö, Sweden.

\section{Author Contributions}

Hjelm K: Conception and design of study, data collection, data analysis and interpretation of results; drafting and preparation of the manuscript for publication.

Berterö C: Conception and design of study, data analysis and interpretation of results; drafting and final approval of the manuscript for publication.

\section{Conflict of Interest}

The authors declare that they have no competing interests.

\section{References}

[1] Hjelm, K. and Berterö, C. (2009) Social Support as Described by Swedish People Diagnosed with Type 2 Diabetes Mellitus. Primary Health Care Research and Development, 10, 26-37. http://dx.doi.org/10.1017/S1463423608000923

[2] Berterö, C. and Hjelm, K. (2010) Social Support as Described by Foreign-Born Persons with Type 2 Diabetes Mellitus and Living in Sweden. Nursing and Health Sciences, 12, 507-514. http://dx.doi.org/10.1111/j.1442-2018.2010.00569.X

[3] International Diabetes Federation. (2009) Diabetes Atlas. 4th Edition. www.diabetesatlas.org

[4] Berry, J.W. (2005) Acculturation: Living Successfully in Two Cultures. International Journal of Intercultural Relations, 29, 697-712. http://dx.doi.org/10.1016/j.ijintrel.2005.07.013

[5] Hull, H. (1979) Migration, Adaptation and Illness: A Review. Social Science \& Medicine, 13, 25-36.

[6] Sundquist, J. (1995) Ethnicity, Social Class and Health. A Population-Based Study on the Influence of Social Factors on Self-Reported Illness in 223 Latin American Refugees, 333 Finnish and 126 South European Labour Migrants and 841 Swedish Controls. Social Science and Medicine, 40, 777-787. http://dx.doi.org/10.1016/0277-9536(94)00146-K

[7] Kirkcaldy, K., Wittig, U., Furnham, A., Merbach, M. and Siefen, R.G. (2006) Migration und Gesundheit. Psychoso- 
ziale Determinanten. Bundesgesundheitsblatt Gesundheitsforschung Gesundheitsschutz, 49, 873-883. http://dx.doi.org/10.1007/s00103-006-0021-9

[8] Lanting, L.C., Joung, I.M., Vogel, I., Bootsma, A.H., Lamberts, S.W. and Mackenbach, J.P. (2008) Ethnic Differences in Outcomes of Diabetes Care and the Role of Self-Management Behaviour. Patient Education and Counselling, 72, 146-154. http://dx.doi.org/10.1016/j.pec.2008.03.008

[9] Charron-Prochownik, D. (1991) Social Support, Chronic Stress, and Health Outcomes in Adolescents with Diabetes (Dissertation). School of Nursing, The University of Michigan, Ann Arbor.

[10] Eriksson, B. and Rosenqvist, U. (1993) Social Support and Glycaemic Control in Non-Insulin Dependent Diabetes Mellitus Patients: Gender Differences. Women \& Health, 4, 59-70. http://dx.doi.org/10.1300/J013v20n04_04

[11] Toljamo, M. and Hentinen, M. (2001) Adherence to Self-Care and Social Support. Journal of Clinical Nursing, 10, 618-627. http://dx.doi.org/10.1046/j.1365-2702.2001.00520.x

[12] Sveriges Officiella Statistik, SOS. (2012) Befolknings Statistik (Official Statistics of Sweden. Population Statistics).

[13] Whiting, D.R., Guariguata, L., Weil, C. and Shaw, J. (2011) IDF Diabetes Atlas: Global Estimates of the Prevalence of Diabetes for 2011 and 2030. Diabetes Research and Clinical Practice, 94, 311-321. http://dx.doi.org/10.1016/j.diabres.2011.10.029

[14] Karasek, R. and Theorell, T. (1990) Healthy Work: Stress, Productivity and the Reconstruction of Working Life. Basic Books Inc. Pub., New York.

[15] Johnson, J. and Hall, E. (1988) Strain, Work Place Social Support, and Cardiovascular Disease: Cross-Sectional Study of a Random Sample of the Swedish Working Population. American Journal of Public Health, 78, 1336-1342. http://dx.doi.org/10.2105/AJPH.78.10.1336

[16] Kahn, R.L. and Antonucci, T.C. (1980) Convoys over the Life Course: Attachment Roles and Social Support. In: Baltes, B.P. and Brim, O.G., Eds., Life Span Development and Behavior, Academic Press, London, 53-86.

[17] Norbeck, J. (1981) Social Support: A Model for Clinical Research and Application. Advanced Nursing Science, 3, 4360. http://dx.doi.org/10.1097/00012272-198107000-00006

[18] Norbeck, J.S., Lindsey, A.M. and Carrieri, V.L. (1981) The Development of an Instrument to Measure Social Support. Nursing Research, 30, 264-269. http://dx.doi.org/10.1097/00006199-198109000-00003

[19] Norbeck, J.S., Lindsey, A.M. and Carrieri, V.L. (1983) Further Development of the Norbeck Social Support Questionnaire: Normative Data and Validity Testing. Nursing Research, 32, 4-9. http://dx.doi.org/10.1097/00006199-198301000-00002

[20] Creswell, J. (2003) Research Design: Qualitative, Quantitative and Mixed Methods Approaches. 2nd Edition, Sage, Thousand Oaks, CA.

[21] Teddlie, C. and Tashakkori, A. (2009) Foundations of Mixed Methods Research: Integrating Quantitative and Qualitative Approaches in the Social and Behavioral Sciences. Sage, London.

[22] Patton, M.Q. (2002) Qualitative Research \& Evaluation Methods. 3rd Edition, Sage, London.

[23] World Medical Association. (2008) WMA Declaration of Helsinki-Ethical Principles for Medical Research Involving Human Subjects. http://www.wma.net/en/ 30publications/10policies/b3/index.html

[24] Berterö, C. (2000) Types and Sources of Social Support for People Afflicted with Cancer. Nursing and Health Sciences, 2, 93-101. http://dx.doi.org/10.1046/j.1442-2018.2000.00044.x

[25] Johansson, I. and Berterö, C. (2002) Types and Sources of Social Support among Cancer Patients: Are There Differences with Respect to Gender? Austral-Asian Journal of Cancer, 2, 3-10.

[26] Krippendorff, K. (2004) Content Analysis: An Introduction to Its Methodology. Sage, London.

[27] Kahn, R.L. (1979) Aging and Social Support. In: Riley, M.W., Ed., Aging from Birth to Death: Interdisciplinary Perspectives, Westview Press, Boulder, 77-91.

[28] Altman, D.G. (1991) Practical Statistics for Medical Research. Chapman \& Hall, London.

[29] Norbeck, J. (1995) Revised Scoring Instructions for the Norbeck Social Support Questionnaire (NSSQ). University of California, San Francisco.

[30] Hjelm, K., Nyberg, P. and Apelqvist, J. (2002) Gender Influences Beliefs about Health and Illness in Diabetic Subjects with Severe Foot Lesions. Journal of Advanced Nursing, 40, 1-13. http://dx.doi.org/10.1046/j.1365-2648.2002.02427.x

[31] Socialstyrelsen. (2010) Nationella Riktlinjer för Diabetesvården. (National Board of Health and Welfare. National Guidelines for Diabetes Care). www.socialstyrelsen.se/nationellariktlinjerfordiabetesvarden.

[32] Hjelm, K., Nyberg, P. and Apelqvist, J. (2002) The Diabetic Foot-Multidisciplinary Management from the Patient's Perspective. Clinical Effectiveness in Nursing, 6, 66-77. http://dx.doi.org/10.1016/S1361-9004(02)00038-9 
[33] Socialstyrelsen. (2012) Nationell Utvärdering 2011—Diabetesvård. Landstingen och Kommunernas Insatser. National Evaluation 2011—Diabetes Care. Achievements by the County Councils and Municipalities. http://www.socialstyrelsen.se/Lists/Artikelkatalog/Attachments/18521/2012-1-1.pdf

[34] Bischoff, A., Bovier, P.A., Isah, R., Francoise, G., Ariel, E. and Louis, L. (2003) Language Barriers between Nurses and Asylum Seekers: Their Impact on Symptom Reporting and Referral. Social Science and Medicine, 57, $503-512$. http://dx.doi.org/10.1016/S0277-9536(02)00376-3

[35] Socialstyrelsen. (2009) Folkhälsorapport. (Public Health Report). http://www.socialstyrelsen.se/Lists/Arikelkatalog/Attachments/8495/2009-126-71_200912671.pdf

[36] Hjelm, K., Bard, K., Nyberg, P. and Apelqvist, J. (2005) Beliefs about Health and Diabetes in men of Different Origin. Journal of Advanced Nursing, 1, 47-59.

[37] Hjelm, K., Bard, K., Nyberg, P. and Apelqvist, J. (2003) Religious and Cultural Distance in Beliefs about Health and Illness in Diabetic Women of Different Origin Living in Sweden. International Journal of Nursing Studies, 40, 627643. http://dx.doi.org/10.1016/S0020-7489(03)00020-8

[38] Hjelm, K., Löndahl, M., Katzman, P. and Apelqvist, J. (2009) Diabetic Persons with Foot Ulcers and Their Perception of Hyperbaric Oxygen Chamber Therapy. Journal of Clinical Nursing, 18, 1975-1985. http://dx.doi.org/10.1111/j.1365-2702.2008.02769.x

[39] Wändell, P.E. and Gåfvels, C. (2007) High Prevalence of Diabetes among Immigrants from Non-European Countries in Sweden. Primary Care Diabetes, 1, 13-16. http://dx.doi.org/10.1016/j.pcd.2006.06.001

[40] Glans, G.F., Elgzyri, T., Shaat, N., Lindholm, E., Apelqvist, J. and Groop, L. (2008) Immigrants from the Middle-East have a Different form of Type 2 Diabetes Compared with Swedish Patients. Diabetic Medicine, 25, 303-307. http://dx.doi.org/10.1111/j.1464-5491.2007.02366.x

[41] Hjelm, K. (1998) Migration, Health and Diabetes Mellitus. Studies Comparing Foreign- and Swedish-Born Diabetic Subjects Living in Sweden (Dissertation). Department of Community Health Sciences, Lund University, Lund.

[42] SFS (1982) Hälso- och Sjukvårdslag. Svensk Författningssamling. [The Health and Medical Service Act]. Ministry of Health and Social Affairs, Stockholm. http://www.sweden.gov.se/sb/d/574/a/23125

[43] Shaw, J.E., Sicree, R.A. and Zimmet, P.Z. (2010) Global Estimates of the Prevalence of Diabetes for 2010 and 2030. Diabetes Research and Clinical Practice, 87, 4-14. http://dx.doi.org/10.1016/j.diabres.2009.10.007

[44] Chaufan, C. (2008) What Does Justice have to do with It? A Bioethical and Sociological Perspective on the Diabetes Epidemic. Advanced in Medical Sociology, 9, 269-300. http://dx.doi.org/10.1016/S1057-6290(07)09011-0

[45] Raphael, D. (2008) Grasping at Straws: A Recent History of Health Promotion in Canada. Critical Public Health, 18, 483-495. http://dx.doi.org/10.1080/09581590802443604

\author{
Abbreviations \\ $\mathrm{DM}=$ Diabetes mellitus \\ DSN $=$ Diabetes specialist nurse \\ NSSQ $=$ Norbeck Social Support Questionnaire \\ PHC = Primary Health Care
}

